\title{
REGISTER STUDIES IN OFFSET LITHOGRAPHY
}

\author{
By C. G. Weber and R. M. Cobb ${ }^{1}$
}

ABSTRACT

A serious economic waste in offset lithography results from lack of knowledge of the optimum printing properties of lithographic papers. The most important losses result from register difficulties, and studies of register have comprised a large part of the research on lithographic papers now being carried on at the Bureau of Standards in cooperation with the Lithographic Technical Foundation. Information on factors influencing register was obtained by making experimental printings in a commercial plant under routine operating conditions. The paper samples used were prepared by cooperating manufacturers, knowledge of the history of manufacture of the papers was supplemented by complete laboratory analyses, and their response to offset printing in controlled atmosphere was observed to find the influence of paper characteristics on register of prints. Most satisfactory register was obtained with the papers that had received the least drastic processing of fibers in manufacture. Internal sizing in machine-finish and coated papers appeared essential, but the amount used, within normal limits, was not important. Thorough conditioning of paper to equilibrium with pressroom atmosphere before the first printing was required to obtain register on subsequent printings, and the longest seasoning period practicable hetween printings was found desirable. Closeness of register was also influenced by variations in pressure, ink, and water used in printing and by uniformity of plates in respect to thickness. An accurate rule of special design for measuring prints and a sword type of hygroscope for determining the hygrometric state of paper were found invaluable in the plant studies.

\section{CONTENTS}

I. Introduction

II. Behavior of paper on the offset press

III. Description and properties of samples

IV. Technique in experimental printings

V. Results of studies of factors influencing register. 1. Atmospheric

2. Mechanical

3. Water and ink

4. Paper properties.-

5. Incidental handling

VI. Summary

VII. Acknowledgment.

\section{INTRODUCTION}

The Bureau of Standards is cooperating with the Lithographic Technical Foundation in a study of the offset lithographic process. The work was undertaken at the request of the foundation. This technical organization of the domestic lithographic industry comprises over 400 members, including lithographic concerns, paper manufacturers and dealers, ink and varnish manufacturers, press and machinery manufacturers, metal lithographers, litho finishers, and photo-composing machine manufacturers. The research is being 
carried on with the advice and active cooperation of an advisory committee from the foundation under the chairmanship of R. F. Reed, director of the department of lithographic research, University of Cincinnati. The study was requested because the industry suffers an enormous annual loss resulting from lack of scientific knowledge concerning the characteristics of paper required for optimum results in offset printing. The principal limiting factor in production is apparently the failure of paper to meet the requirements of the modern high-speed offset press, and it has been conservatively estimated that not over 75 per cent of the theoretical production of the average press is attained for that reason.

Preliminary investigational work was previously done by the bureau ${ }^{2}$ for the purpose of finding the principal difficulties in offset lithography for which paper is wholly or partly responsible. A survey was made of 31 lithographic plants, and the results served as a basis for planning the present study. Misregister was the most serious difficulty found; therefore, a study of the register of prints was undertaken first, and this article deals with some results already obtained.

A series of practical printing tests were made in the Buffalo, N. Y., plant of the American Lithographic Co. under routine operating conditions to isolate and study the important factors influencing the closeness of register. An air-conditioned pressroom was selected in order to eliminate variables due to changes in atmospheric humidity. By using specially prepared papers, of which the history of preparation as regards composition, degree and kind of sizing, degree of hydration of fibers, and fiber length were known, information relative to the influence of paper characteristics on closeness of register was developed. Printing identical papers on a press with controlled variations of such factors as pressure, water, and ink gave information on the effects of press variables. The papers used in experimental printings were subjected to complete laboratory tests of physical properties, composition, water penetration, and behavior under tension at different humidities to obtain information for correlation with results developed relative to the response of the papers to the printing tests.

\section{BEHAVIOR OF PAPER ON THE OFFSET PRESS}

The offset lithographic process is indirect in that the print is transferred from the plate to the paper by means of a rubber blanket. Three cylinders of the same dimensions run one against another in fixed positions with a gear on the end of each engaged with a similar gear on the next. The cylinders are driven through these gears, providing the same speed of rotation for all. They rest one against another with fixed pressure on narrow metal bands, known as bearers, at the ends of the cylinders. The plate with a positive image is clamped around the first or plate cylinder and this bears against the second or blanket cylinder which is covered with a thin rubber blanket. The blanket cylinder bears against a third cylinder known as the impression cylinder. In operation, the plate after being progressively moistened and inked, prints on the rubber blanket which in turn deposits the print on the paper pressed against it by the impression cylinder.

2 The preliminary work was done by F. H. Thurber, formerly an associate scientist at the Bureau of Standards. 
The dimensions of paper may change during passage through the press or between printings, and the nature and extent of such changes determine, largely, the closeness of register in subsequent printings. Changes in length in the short or around-the-cylinder direction are relatively unimportant because any reasonable change in this dimension can be compensated for by press adjustments. However, changes in dimension in respect to the length along the back edge (long direction) always result in register difficulties. In passage through the press, paper does one of three things in respect to length along the back edge before the instant of taking the print. It shortens or "pulls in," remains unchanged, or lengthens by "fanning-out" under stress. If the paper has stretched before taking the impression and recovers afterward with resultant contraction of the printed design, the resulting print will be shorter than the plate image and, if after taking the print the paper expands, the print will be longer than the image.

Register will be obtained regardless of changes in the paper, if at the instant of taking the succeeding print the paper responds in such a manner as to bring the preceding print back to exactly blanket image length. Misregister will occur if the preceding print is not brought to image length. Hence, paper can change in length as measured and the print stay in register; while paper may show no change in length as measured and yet be out of register. A consideration of the mechanics involved indicates that there is much more chance of a short first print stretching or "fanning-out" to plate image length, to obtain register as it takes the next print, than there is of a long print being shortened or "pulled in" to plate image length as it takes the next print. Therefore, papers that expand after taking a print, that is, "print longer than the plate image," are particularly prone to give misregister.

\section{DESCRIPTION AND PROPERTIES OF THE EXPERIMENTAL PAPERS}

The papers used in the experimental printings were studied in the laboratory in order to obtain complete information for correlation with their response to the printing processes. Through the cooperation of paper manufacturers, four papers of the same composition with different degrees of beating, the same papers with surface sizing, three coated papers differing as to the degree of sizing in the raw stock (paper before coating), and three extra strong machinefinish papers differing as to degree of internal sizing were made available for the studies. The properties of the papers as indicated by the test data for them are given in Table 1. All were chemical wood papers.

Since mechanical deformation of paper is a factor in obtaining register, laboratory studies were made of the elongation of various samples of lithographic papers under tension. Eleven papers were conditioned and tested in atmospheres of $30,45,65$, and 75 per cent relative humidity. Tensions of from 9 to $455 \mathrm{~g}$ were applied to specimens $15 \mathrm{~mm}$ wide and the elongation for each increment of tension was observed by means of a horizontal microscope. The results did not indicate any significant differences in elongation between the various samples tested which included machine-finish litho, supercalendered litho, coated litho, and surface-sized paper. 
The greatest differences in the elongation of the different papers occurred at 75 per cent relative humidity and there the widest difference was less than 0.1 per cent for the cross direction. Differences for the machine direction were much smaller. Such differences in expansion are not significant; however, the relation of relative humidity to expansion was significant. The minimum variation between the expansions of the different papers occurred at 45 per cent relative humidity and changes in expansion for changes in relative humidity were of smaller magnitude in the vicinity of 45 per cent relative humidity than at other humjdities used. These results indicate definite advantages in the selection of an atmosphere of approximately 45 per cent relative humidity for lithographic plants.

TABLE 1.-Test data of experimental papers

\begin{tabular}{|c|c|c|c|c|c|c|c|c|c|c|c|c|}
\hline \multirow{3}{*}{ Sample No. } & \multirow{3}{*}{\begin{tabular}{|} 
Weight, \\
25 by 40 \\
inches, \\
500 \\
sheets
\end{tabular}} & \multirow{3}{*}{$\begin{array}{l}\text { Thick } \\
\text { ness }\end{array}$} & \multirow{3}{*}{$\left|\begin{array}{l}\text { Bursting } \\
\text { strength }^{3}\end{array}\right|$} & \multicolumn{2}{|c|}{$\begin{array}{l}\text { Folding endur- } \\
\text { ance }{ }^{1}\end{array}$} & \multicolumn{4}{|c|}{ Tensile properties ${ }^{2}$} & \multirow{3}{*}{$\begin{array}{l}\text { Water } \\
\text { resist- } \\
\text { ance } \\
\text { (Dry- } \\
\text { indica- } \\
\text { tor } \\
\text { method) }\end{array}$} & \multirow{3}{*}{ Ash } & \multirow{3}{*}{ Opac } \\
\hline & & & & \multirow{2}{*}{$\begin{array}{l}\text { Ma- } \\
\text { chine } \\
\text { direc- } \\
\text { tion }\end{array}$} & \multirow{2}{*}{$\begin{array}{l}\text { Cross } \\
\text { direc- } \\
\text { tion }\end{array}$} & \multicolumn{2}{|c|}{$\begin{array}{l}\text { Breaking } \\
\text { load }\end{array}$} & \multicolumn{2}{|c|}{$\begin{array}{l}\text { Elongation } \\
\text { at rupture }\end{array}$} & & & \\
\hline & & & & & & $\begin{array}{l}\mathrm{Ma}- \\
\text { chine }\end{array}$ & Cross & $\begin{array}{l}\text { Ma- } \\
\text { chine }\end{array}$ & Cross & & & \\
\hline & \begin{tabular}{|r} 
Pounds \\
78.1 \\
74.3 \\
73.8 \\
69.2 \\
79.8
\end{tabular} & \begin{tabular}{|r|} 
Inch \\
0.0049 \\
.0042 \\
.0044 \\
.0040 \\
.0018
\end{tabular} & $\begin{array}{r}\text { Points } \\
24.3 \\
21.1 \\
21.4 \\
20.7 \\
33.0\end{array}$ & $\begin{array}{r}\text { Double } \\
\text { folds } \\
52 \\
18 \\
25 \\
14 \\
62\end{array}$ & $\begin{array}{c}\text { Double } \\
\text { folds } \\
15 \\
11 \\
10 \\
11 \\
29\end{array}$ & $\begin{array}{l}k g \\
6.9 \\
5.5 \\
5.9 \\
5.2 \\
8.5\end{array}$ & $\begin{array}{l}k g \\
3.3 \\
3.0 \\
3.0 \\
2.9 \\
4.1\end{array}$ & $\begin{array}{r}\text { Per } \\
\text { cent } \\
1.5 \\
1.6 \\
1.1 \\
1.3 \\
1.7\end{array}$ & $\begin{array}{r}\text { Per } \\
\text { cent } \\
3.2 \\
3.7 \\
2.6 \\
3.9 \\
3.7\end{array}$ & $\begin{array}{c}\text { Seconds } \\
53.7 \\
31.9 \\
44.1 \\
31.5 \\
48.4\end{array}$ & $\begin{array}{r}\text { Per } \\
\text { cent } \\
9.9 \\
11.7 \\
9.9 \\
11.5 \\
9.5\end{array}$ & $\begin{array}{c}\text { Per } \\
\text { cent } \\
96.2 \\
96.2 \\
95.2 \\
94.4 \\
95.2\end{array}$ \\
\hline & $\begin{array}{l}82.0 \\
77.7 \\
75.6 \\
70.2 \\
75.3\end{array}$ & $\begin{array}{l}.0049 \\
.0047 \\
.0047 \\
.0032 \\
.0036\end{array}$ & $\begin{array}{l}25.9 \\
27.9 \\
25.1 \\
21.7 \\
22.8\end{array}$ & $\begin{array}{l}12 \\
46 \\
14 \\
55 \\
48\end{array}$ & $\begin{array}{l}15 \\
17 \\
10 \\
10 \\
16\end{array}$ & $\begin{array}{l}7.6 \\
8.0 \\
7.1 \\
5.5 \\
5.9\end{array}$ & $\begin{array}{l}3.9 \\
3.8 \\
3.9 \\
2.6 \\
2.8\end{array}$ & $\begin{array}{l}1.5 \\
1.3 \\
1.5 \\
2.3 \\
2.1\end{array}$ & $\begin{array}{l}3.8 \\
3.7 \\
4.2 \\
3.1 \\
3.6\end{array}$ & $\begin{array}{l}63.3 \\
43.4 \\
55.3 \\
19.1 \\
23.1\end{array}$ & $\begin{array}{r}12.1 \\
9.1 \\
10.5 \\
35.7 \\
33.6\end{array}$ & $\begin{array}{l}96.1 \\
94.4 \\
95.6 \\
95.1 \\
95.5\end{array}$ \\
\hline$\cdots$ & $\begin{array}{l}76.2 \\
56.3 \\
54.4 \\
53.9\end{array}$ & $\begin{array}{l}.0037 \\
.0033 \\
.0034 \\
.0032\end{array}$ & $\begin{array}{l}21.2 \\
20.0 \\
19.6 \\
20.1\end{array}$ & $\begin{array}{l}38 \\
28 \\
24 \\
26\end{array}$ & $\begin{array}{l}12 \\
12 \\
10 \\
11\end{array}$ & $\begin{array}{l}5.4 \\
5.9 \\
5.5 \\
5.5\end{array}$ & $\begin{array}{l}2.6 \\
2.8 \\
2.5 \\
2.5\end{array}$ & $\begin{array}{l}2.1 \\
1.5 \\
1.6 \\
1.5\end{array}$ & $\begin{array}{l}3.4 \\
3.3 \\
3.4 \\
4.0\end{array}$ & \begin{tabular}{l|}
26.3 \\
12.1 \\
19.3 \\
25.9
\end{tabular} & $\begin{array}{r}35.2 \\
7.2 \\
8.0 \\
8.0\end{array}$ & $\begin{array}{l}96.4 \\
87.7 \\
88.4 \\
89.9\end{array}$ \\
\hline
\end{tabular}

1 For test specimen, $15 \mathrm{~mm}$ wide and $90 \mathrm{~mm}$ between jaws.

2 For test specimen, $15 \mathrm{~mm}$ wide and $100 \mathrm{~mm}$ between jaws.

3 Bursting pressure in pounds per square inch through a circular orifice 1.2 inches in diameter.

Description of special papers

\begin{tabular}{r|l}
$\begin{array}{c}\text { Sam- } \\
\text { ple } \\
\text { No. }\end{array}$ & \\
\hline 1 & Machine-finish litho, light beating, light jordanning. \\
2 & Machine-finish litho, light beating, heavy jordanning. \\
3 & Machine-finish litho, normal beating, light jordanning. \\
4 & Machine-finish litho, normal beating, heavy jordanning. \\
5 & No.1 surface sized with starch. \\
6 & No. 2 surface sized with starch. \\
7 & No. 3 surface sized with starch. \\
8 & No. 4 surface sized with starch. \\
10 & Coated litho, no sizing in raw stock. \\
11 & Coated litho, one-half normal sizing in raw stock. \\
13 & Extra strono, normal sizing in raw stock. \\
14 & Extra strong machine-finish litho with no sizing. \\
15 & Extra strong machine-finish litho with one-half normal sizing. \\
12 & Commercial machine-finish litho with normal sizing. \\
\hline
\end{tabular}

Note.-The papers were cut 38 by 52 inches with the long dimension in the machine direction of the paper. 


\section{TECHNIQUE IN EXPERIMENTAL PRINTINGS}

In the experimental printings to determine the relation between paper characteristics and closeness of register, the samples of experimental papers were inserted in the center of the piles and printed with papers being used for regular commercial multicolor printings requiring very close register. To determine the effects of press variables, one press was set aside for experimental work. This press was made ready with the plate at exactly bearer height and with a minimum pressure between the blanket and plate. The printing pressure was varied within closely controlled limits, while printing with a dry plate, with water alone, and with ink and no water to find the extent of effect of each of those factors on register.

Changes in paper dimensions were determined by means of a rule designed for measuring the displacement of reference marks on large sheets of paper. (Fig. 1.) It is equipped with two magnifying glasses, each with a small glass reticule having a vertical cross hair mounted directly underneath. One magnifier may be placed at any point within the range of the scale (24 to 64 inches) and readily set so that its cross hair will coincide with any division on the scale. The other magnifier (fig. 2) is set over the second reference point by means of micrometer adjustment. The distance between the reference points may then be read to 0.001 inch.

Data relative to dimension changes of papers were determined by measuring distances between register marks on the plate, distances between reference marks on the paper before printing and after each printing, and the distances between register prints after each printing. Length of plate image in the around-the-cylinder direction was measured on the press with a thin steel tape.

Since all changes in moisture content of paper are accompanied by dimension changes, a very careful check was maintained on the hygrometric state of the papers, especially in respect to the surrounding atmosphere. The sword type of paper hygroscope ${ }^{3}$ was invaluable as a tool for determining quickly whether or not paper was in equilibrium with the pressroom atmosphere. The instrument resembles a sword, the blade of which contains a hygroscopic element. Expansion and contraction of the element actuate the pointer of an indicating device mounted on the handle of the instrument. The hygroscope is first set for the pressroom atmosphere by waving it in the air until the pointer comes to rest and then turning the dial to the position where the zero reference mark is directly under the pointer. The blade is then inserted between the sheets of the pile of paper to be tested, and left until the pointer comes to rest. Movement of the pointer from the zero reference mark indicates that the paper is not in equilibrium with the surrounding atmosphere.

\section{RESULTS OF STUDIES OF FACTORS INFLUENCING REGISTER}

The results of the printings in respect to permanent dimension changes (figs. 3 and 4 ), the relation of length of first print to plate image length with subsequent printings (fig. 7), and effects of press variables (figs. 5 and 6), are presented graphically.

${ }^{3}$ Robert F. Reed, The Paper Hygroscope, Sales Bull. No. 1. Research Series No. 6, Lithographic Technical Foundation, 220 East Forty-second Street, New York, N. Y. 
A number of important factors were found to affect register in lithographic printing when constant atmospheric conditions were maintained and the response of papers of known history to a number of the factors was studied. Some study of mechanical factors was

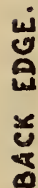

ร

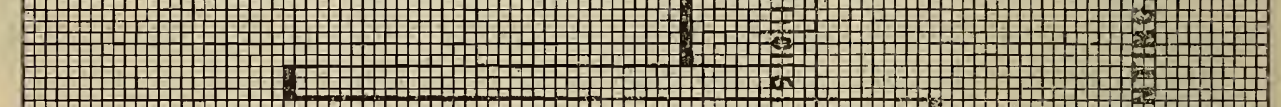

5

$\underline{a}$

0

0

$n$

崩

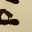

U

$\frac{1}{a}$

亗

E

(

๓

$(\mathrm{m}$

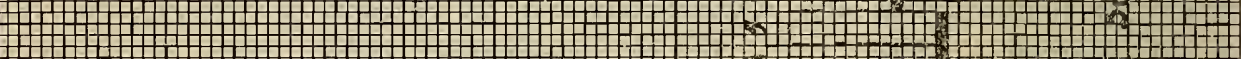

( )

ऍ

\}

๓๐

(\)

๓

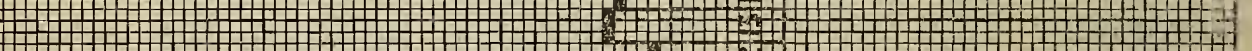

\\)

$(\mathrm{C}$

\(2)

(

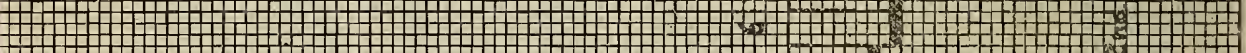

\}

¿

$\infty$

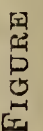

5

$\frac{\bar{\alpha}}{a}$

Z

2

$\frac{2}{n}$

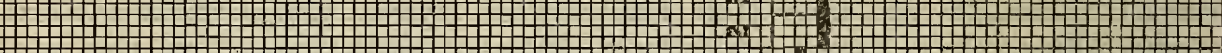

\}

\

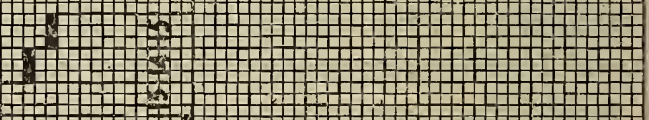

¿

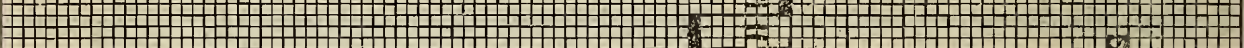

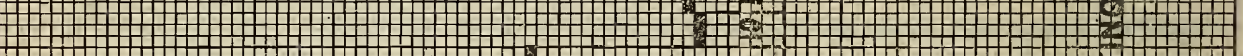

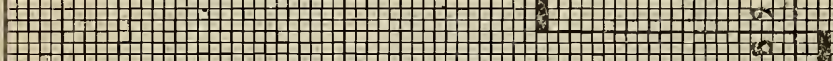

2

H+1

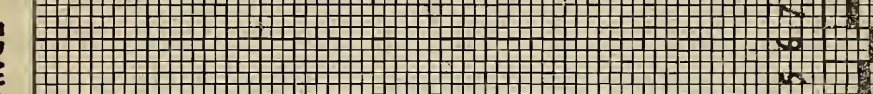

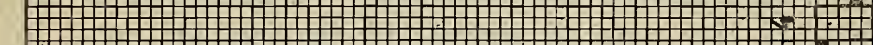

ऍ

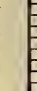

\#

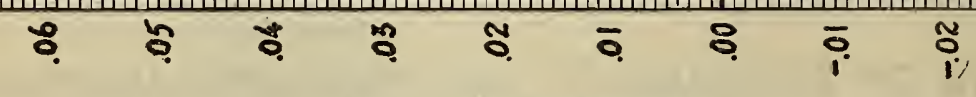

S3HONI NI 3ONGHO 7Ұ1OL

necessary in order to eliminate the variables not influenced by paper characteristics.

\section{ATMOSPHERIC}

The moisture content of the commercial papers as received at the plant was found to vary from 2.8 to 6.2 per cent while that required for hygrometric equilibrium with the press room atmosphere was 


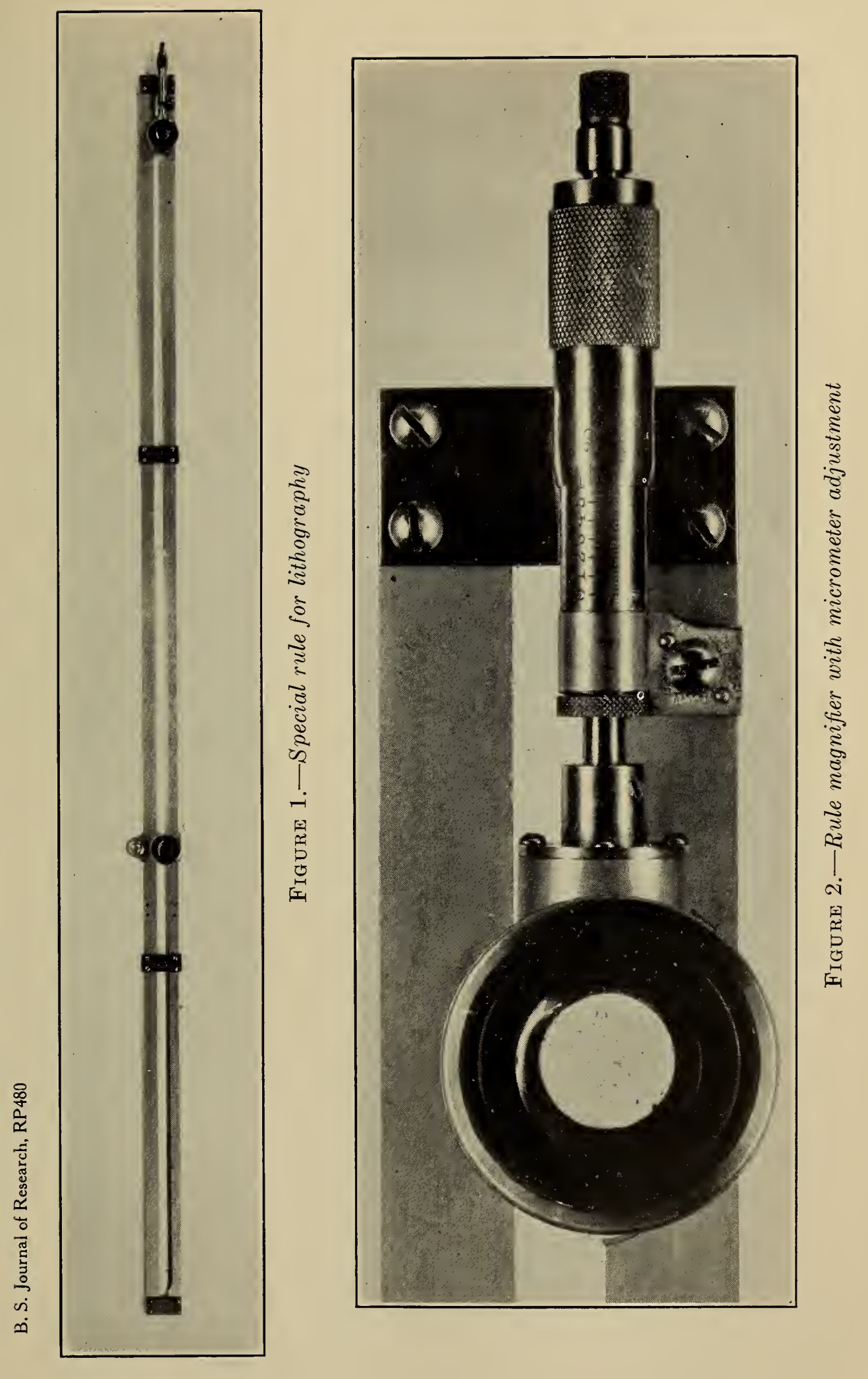


approximately 5.0 per cent. When cases of paper having a moisture content more than 1 per cent below room equilibrium were opened and exposed to room atmosphere in the pile, the exposed edges and top of the pile absorbed moisture and waves and wrinkles quickly developed from expansion of those portions. Excessive conditioning

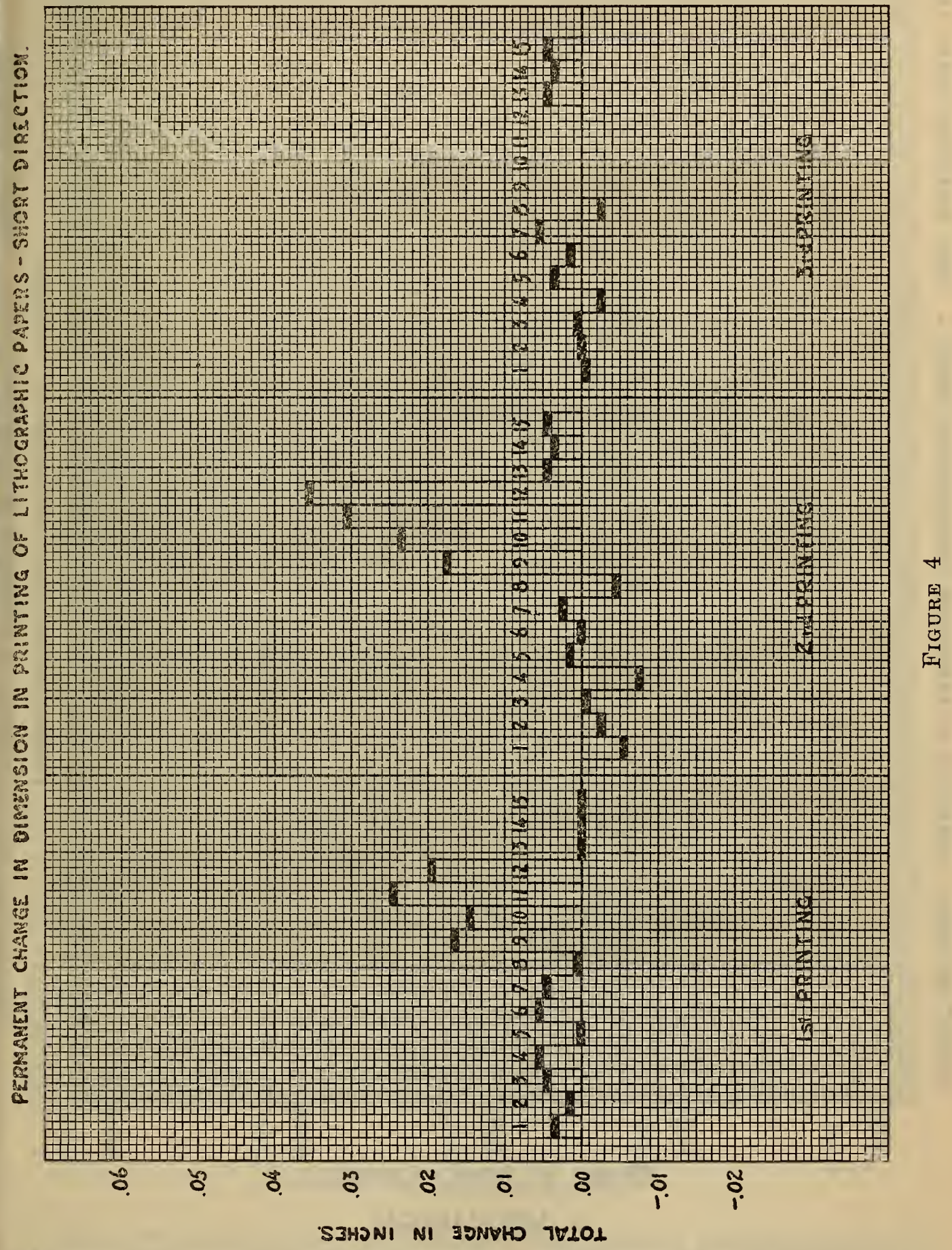

time was required for removal of such wrinkles and when they were not removed, misregister resulted as a result of the paper distortion. The benefits of controlled atmosphere in the press room are, of course, lost if the paper is not thoroughly conditioned before the first printing. It is important to remember that papers differ as to time required to 
thoroughly condition them. Certain papers, such as moisture-resistant bond paper or paper badly out of equilibrium with press room atmosphere, require extra conditioning time.

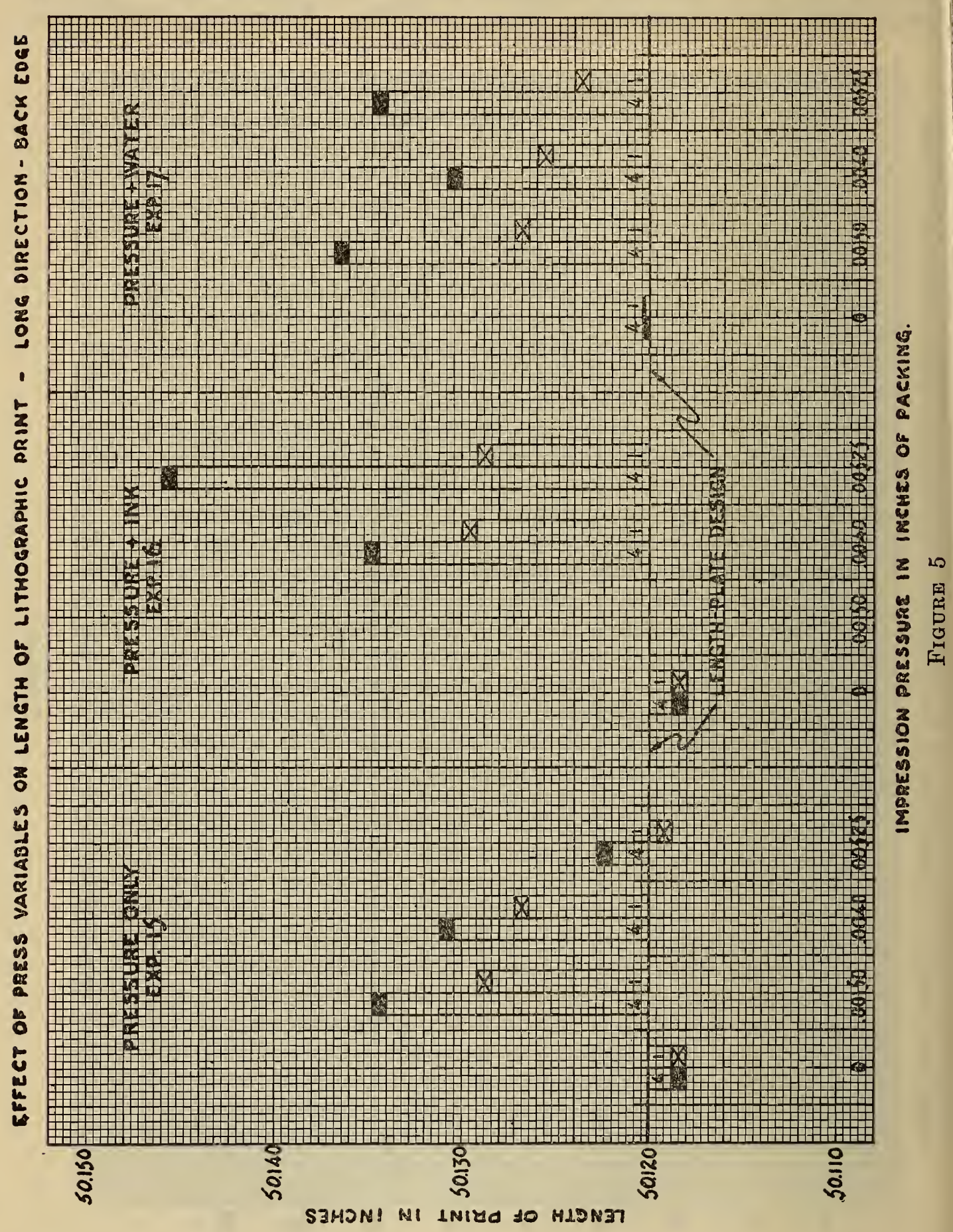

\section{MECHANICAL}

Thickness of plates and the stress applied in clamping them on the cylinder both influence the effective image length. The length is increased due to curvature in bending the plate around the cylinder and the amount of increase varies with the plate thickness, although no mathematical formula seems to apply. Increase in length of plate due to mechanical stress in clamping it varies inversely with its thick- 
ness. All plates measured were from 0.050 to 0.085 inch longer in 35 inches in the around-the-cylinder direction, when clamped on the cylinder than when flat. From these considerations, thickness standardization for plates appears very important.

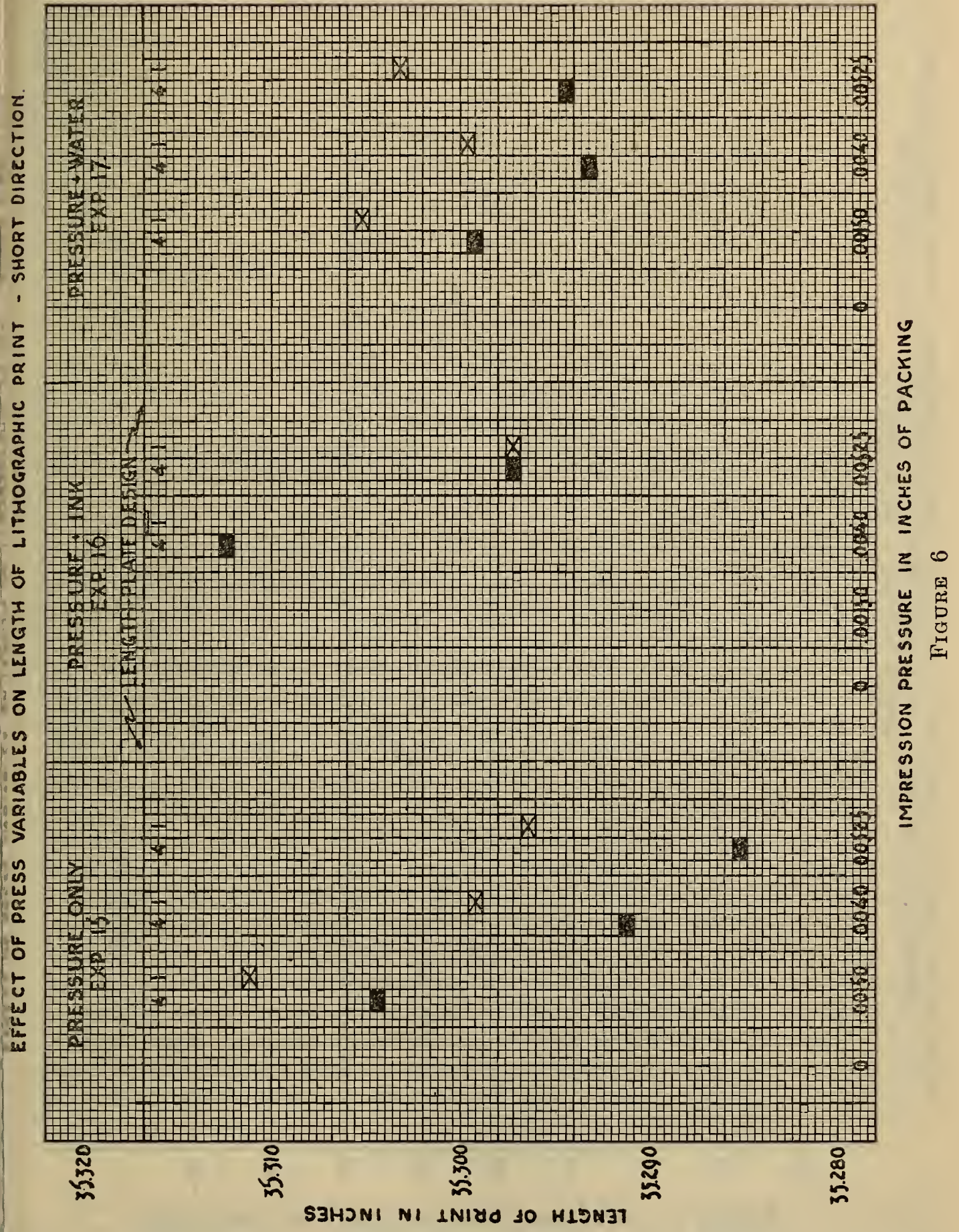

Studies were not made to determine the effects of packing under the plate and blanket. In the studies of other factors, the plate was built up to bearer height and the blanket overpacked 0.0025 to 0.003 inch, although it is common practice to build both plate and blanket above bearer heights. The bearers were 18 inches in diameter. With neither ink nor water on the plate, increase in pressure between the 
blanket and paper decreased slightly the excess in length of print over plate image along the back. In the short direction, the print was shortened. With ink alone on the plate, the effect of pressure was less along the back edge, but was little changed in the short direction.

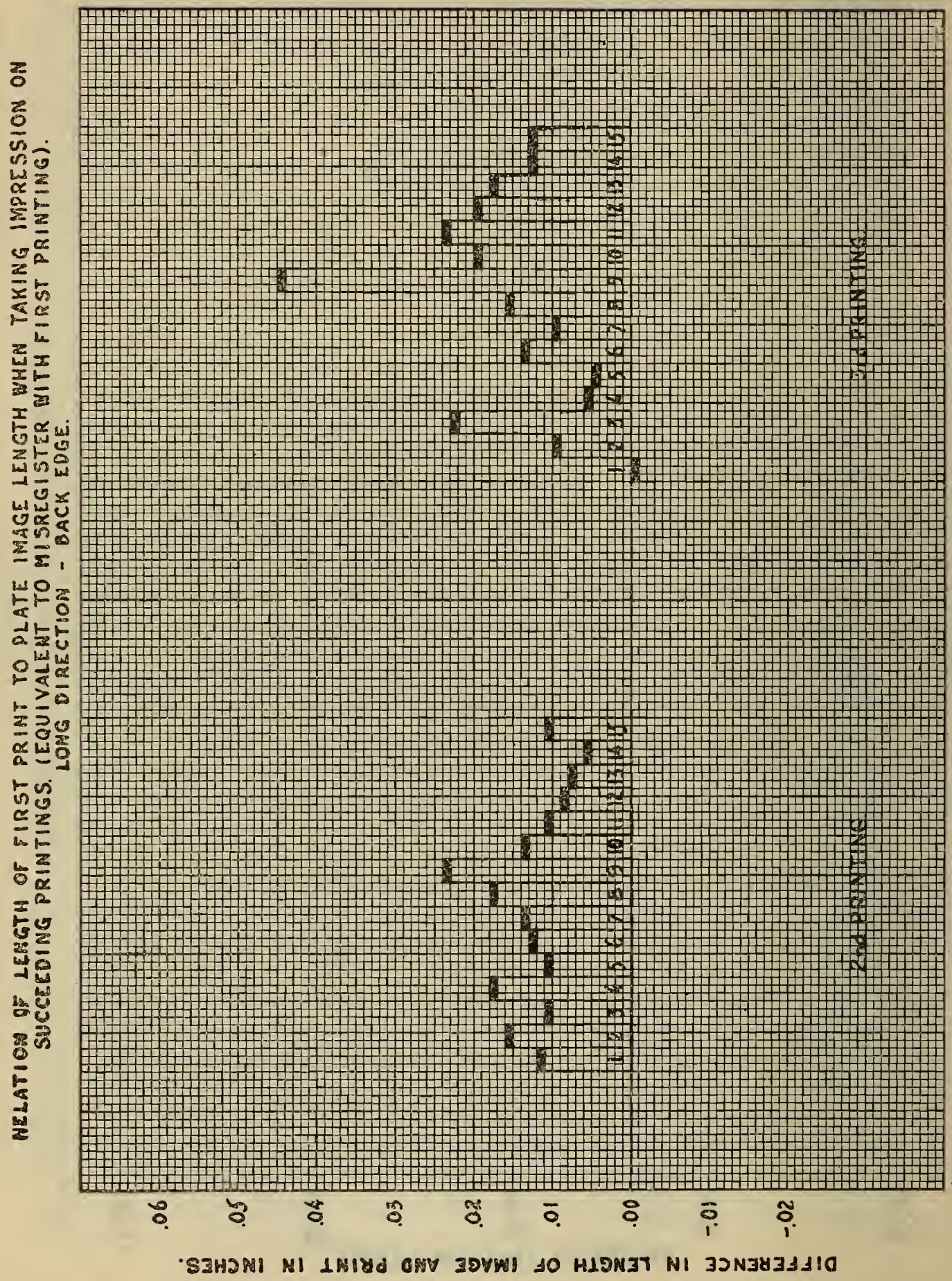

With water alone on the plate, the effects of increased pressure were less in both directions.

A print may be lengthened in the short or around-the-cylinder direction by removing packing from beneath the plate and placing it under the blanket. The increased length is caused by slippage introduced by increasing the circumference and thereby the peripheral 
speed of the blanket, and decreasing the peripheral speed of the plate by decreasing its circumference. This slippage is probably taken up largely by blanket creep, but it results in an increase in the length of print corresponding to the difference between the effective cylinder circumferences. Contrary to rather common belief, the increase in plate image length due to change in curvature by removing packing was too slight to require consideration. However, the difference in peripheral speed between plate and blanket introduced by transferring 0.003 inch packing from the plate to the blanket was calculated to be 0.0191 inch in 35 inches. The length of print in the around-thecylinder direction may also be increased by pasting a sheet of paper on the back cylinder. By this method the peripheral speed of the paper is increased, introducing between the blanket and paper a creeping or slippage which results in a longer print.

\section{WATER AND INK}

The water used on the press had two effects on the paper passing through the press. The immediate effect, due to absorption of moisture, was an expansion of about 0.005 inch in 50 inches. When conditioned until equilibrium with the atmosphere was again reached, the paper shrank to about 0.005 inch less than its original length, a phenomenon that has not been satisfactorily explained. Ordinarily, paper left in piles between printings is in a condition somewhere between the two extremes at the second printing. The amount of water used is apparently of little importance in respect to action of the paper during passage through the press. During a normal first printing, the moisture content increased about 0.1 per cent. Doubling the amount of water used had no serious immediate effect on the expansion and contraction of the paper.

Ink affects register to a degree contingent on the extent of the area covered. When printing large solid ink areas, the prints were longer than the plate image along the back edge, possibly a result of lubricating action of the ink in permitting the blanket to fan-out without taking the paper with it. Second prints on first prints containing large solid ink areas on which the ink was not entirely dry were short in the around-the-cylinder direction. This may have been due to an effect of the moist ink on the friction between the paper and the blanket, or it may have been due to increased elasticity of the paper, permitting more temporary stretch in the cross direction of the sheet. Ink tackiness was not studied, but is apparently important. These effects of water, ink, and pressure on length of print are shown graphically in Figure 5 (long direction, back-edge) and Figure 6 (short direction).

\section{PAPER PROPERTIES}

The degree of hydration and length of fibers of paper, which depend on the beating ${ }^{4}$ and jordanning ${ }^{5}$ the fibers have been given during manufacture, is extremely important. In studying the influence of

\footnotetext{
4 Beating is the term applied to mechanical treatment given to paper-making materials, suspended in water, to prepare them for forming a sheet on the paper machine. Beating separates, brushes, and fraysout the fibers and causes them to absorb water by a process known as "hydration."

$\checkmark$ Jordanning is a refining process that usually follows beating to complete the preparation of the materials for forming a paper of the desired character. In the jordan the fibers are freed from lumps and cut to the desired length.
}

$$
132919-32-11
$$


these factors on register, seven of the papers having the same composition, but with different beating, jordanning, and sizing treatments were inserted in the center of a pile of paper on a nine singlecolor run which required hairline register, and not separated from the pile until the nine printings were finished. The length of the first color (yellow) impression on each paper was measured and compared with those of the regular run. The sample with the least drastic beating and jordanning in its manufacture had the shortest first-color impression along the back edge and was the best as regards register, while the sample with the most drastic treatment in those respects was poorest. The sample with the least beating and jordanning had the longest first-color impression, hence was best in repsect to register in the around-the-cylinder direction, while the sample having the most drastic treatment was again poorest.

Samples of the eight papers (Nos. 1 to 8, Table 1) were also inserted in the center of a pile of commercial paper and printed six colors, two colors each printing. In these tests, as in the preceding, the sample that had the least drastic beating and jordanning was best in respect to register, and misregister increased with increased beating and jordanning. (Figs. 3 and 4.) These results indicate the desirability of manufacturing papers for lithography with the least beating and jordanning necessary to obtain satisfactory strength and printing surface.

The degree of internal sizing and the presence of surface sizing are factors. Surface sizing decreases slightly the dimension changes during printing, but did not have marked effect on the samples available. Increasing the internal (beater) sizing of coated papers reduced the tendency to stretch along the back edge, but was not as effective in the short direction. (Nos. 9, 10, 11, figs. 3, 4, 7.) The effects on register were slight. Paper with one-half normal sizing remained in register best in both directions. With extra strong machine-finished papers, increased degree of internal sizing improved the register on the back edge, but did not improve it in the short direction. (Nos. $13,14,15$, figs. 3,4 , and 7 .) One-half normal sizing was practically as effective as normal sizing. It appears that while internal sizing is desirable for good register, the amount used, within normal limits, was not a very important factor.

\section{INCIDENTAL HANDLING}

The time that paper is allowed to season between printings will influence results in subsequent printings. In a conditioned plant, it was found that the longest seasoning period practicable is desirable since the seasoning period permits an even distribution of moisture picked up in passing through the press and allows the paper to recover from stresses set up in printing.

Register can be controlled within certain limits by set-up of the feeders. By certain adjustments, a "dip" may be introduced in the sheet that will materially shorten long prints already on the sheet, and at the same time lengthen to somewhat smaller extent the current print. In one case noted, a red color found to be printing 48.866 inches along the back edge was 0.028 inch longer than a succeeding black. By pressing down on the sheet with a 1-inch roller 10 inches inside the edge, while the paper was being fed to the press, the current 
black print was lengthened 0.004 inch along the back edge and the paper was drawn in to shorten permanently the preceding red print 0.020 inch. The resulting misregister was therefore reduced to 0.004 inch. Such methods can be employed satisfactorily only on the last printing.

\section{SUMIMARY}

In the plants having controlled atmosphere, thorough conditioning of paper is essential if the full benefits of atmospheric control are to be obtained. The moisture content of paper to be used in such plants should be adjusted at the paper mill to approach equilibrium with the pressroom conditions in order to facilitate conditioning. Paper badly out of equilibrium should be hung immediately after unwrapping. The hygroscopic condition of paper with reference to pressroom atmosphere in which it is unwrapped can be quickly determined with the sword-type hygrometer. The longest seasoning period practicable between printings is desirable for uniform results, and there appear to be definite advantages in the selection of 45 per cent relative humidity for lithographic plants. For the plant without controlled atmosphere, every precaution should be taken to protect paper from atmospheric changes after starting the first printing. The paper should be protected between printings by covering with waterproof wrappers.

Thickness standardization of plates was found important to insure uniformity of plate stretch in clamping plates in place. With neither ink nor water on the plate, changes in printing pressure affected register only slightly and the effects of pressure variations were even less with ink alone and with water alone. Prints may be lengthened in the around-the-cylinder direction by transferring packing from the plate to the blanket or adding packing to the impression cylinder. The amount of water used did not appear important as doubling the amount used had no serious immediate effects. The effect of ink was contingent on the extent of the area covered, the presence of large solid ink areas resulting in increased register troubles.

Paper characteristics are important. The best register was obtained on the papers that had received the least drastic beating and jordanning in manufacture. Internal sizing was desirable but the amount used, within normal limits, was relatively unimportant. Approximately one-half normal sizing gave best results. The presence of surface sizing had no marked effect on the papers studied.

The closeness with which the imprint length on the paper agrees with the length of the plate design on the first color will indicate the closeness of register that may be expected with subsequent printings. By measuring the first sheets printed on the first color, information may be obtained at the start of any multicolor "job" that will indicate whether register trouble will be encountered in succeeding printings. A first print on the paper longer than the plate design along the back edge is always indicative of register troubles. The special rule described should be of great value to the lithographer for use here in forestalling trouble. 


\section{ACKNOWLEDGMENT}

Acknowledgment is made of the invaluable assistance in this study of the advisory committee from the Lithographic Technical Foundation; of the Lowe Paper Co., who made the services of Miss R. M. Cobb available; of the American Lithographic Co. in the experimental printings; and of the following paper manufacturers who furnished the experimental papers: Dill \& Collins Co., Rex Paper Co., West Virginia Pulp \& Paper Co.

Washington, July 12, 1932. 